\title{
Comparison of lidocaine, huffing maneuver and combination of both in prevention fentanyl induced cough before induction of anesthesia: a double-blind, prospective, randomized placebo-controlled study
}

\author{
Laleh Dehghanpisheh, Mohammadhossein Eghbal, Fatemeh Bagheri Baravati and Pooya Vatankhah*
}

\begin{abstract}
Background: Intravenous bolus injection of fentanyl has been frequently reported to be associated with cough reflex during patient anesthesia. However, the search for the most effective protocol continues. This study aimed to compare the effect of reducing cough reflex after injection of fentanyl in a fusion protocol by combining the injections of lidocaine and Huffing maneuver and comparing with a placebo control group, before anesthesia induction.

Methods: This prospective randomized controlled trial study was performed on 400 patients who were divided into four groups of combined protocol (group 1), lidocaine group (group 2), Huffing maneuver group (group 3), and the control receiving normal saline (group 4). Then patients were injected with $2.5 \mathrm{\mu g} / \mathrm{kg}$ fentanyl and monitored for 2 min regarding their cough reflex, as well as the severity.

Results: In group one, 9 patients (9\%), in group two, 45 patients (45\%), 22 patients (22\%) in group three, and in group four, 75 patients (75\%), developed cough reflex following fentanyl injection. Also, 13 patients (13\%) developed moderate and 4 (4\%) developed severe coughs in the control group reported, while no reports of severe or moderate cough were among the intervention groups. There was a significant difference between the intervention group and the control group both in terms of the rate and severity of the fentanyl-induced cough.

Conclusion: By using a combination of lidocaine injection along and Huffing maneuver, better results can be obtained in reducing the frequency, and also the severity of cough followed by fentanyl injection.
\end{abstract}

Trial registration: The trial was registered with IRCT.IR (09/03/2018-No. IRCT20141009019470N74).

Keywords: Fentanyl, Lidocaine, Huffing maneuver, Cough, Combination protocol

* Correspondence: Pvatankhah@sums.ac.ir

Anesthesiology and Critical Care Research Center, Shiraz University of

Medical Sciences, Shiraz, Iran

(c) The Author(s). 2021 Open Access This article is licensed under a Creative Commons Attribution 4.0 International License, which permits use, sharing, adaptation, distribution and reproduction in any medium or format, as long as you give appropriate credit to the original author(s) and the source, provide a link to the Creative Commons licence, and indicate if changes were made. The images or other third party material in this article are included in the article's Creative Commons licence, unless indicated otherwise in a credit line to the material. If material is not included in the article's Creative Commons licence and your intended use is not permitted by statutory regulation or exceeds the permitted use, you will need to obtain permission directly from the copyright holder. To view a copy of this licence, visit http://creativecommons.org/licenses/by/4.0/. The Creative Commons Public Domain Dedication waiver (http://creativecommons.org/publicdomain/zero/1.0/) applies to the data made available in this article, unless otherwise stated in a credit line to the data. 


\section{Introduction}

Fentanyl-induced cough (FIC) is amongst the most common complications of anesthesia induction by intravenous bolus administration of fentanyl, which has been reported in 18 to $65 \%$ of patients [1, 2]. Although this phenomenon is usually brief and self-limiting, during anesthesia induction, coughing is undesirable since it is associated with increased intracranial (ICP), intraocular, and intra-abdominal pressures. Also, multiple conjunctival and periorbital petechiae can be triggered by extreme FIC [3] and contribute to upper airway obstruction that may need urgent intervention [4]. Hence, prevention of FIC is of much clinical value.

Although multiple FIC-responsible mechanisms have been proposed, the exact mechanism remains unknown. Central sympathetic outflow could be blocked by fentanyl, thus stimulating the vagus nerve. This vagal activity change has been identified as a potential cause of cough and reflex bronchoconstriction [5, 6]; However, a study by Lui Ping-Wing et al. [5] reported that cough reflex after opioid injection is not likely to be vagally mediated because atropine pretreatment does not affect it. Hence, further pathophysiological studies in this area are required for the better understanding of the exact mechanism of FIC.

Lidocaine was successful in suppressing FIC in a metaanalysis by Kim et al., regardless of dose [7]. The mechanism by which lidocaine suppresses mechanically and chemically mediated cough reflex remains unclear, although it has been proposed that depression in brainstem activity is a possibility [8].

The Huffing maneuver is a gentle, voluntary maneuver that opens the glottis following a high-pressure exhalation, and the air inside the upper airways is emptied along with secretions. This maneuver causes the opening of closed alveoli, reduces atelectasis, and increases the functional residual capacity of the lungs $[9,10]$. Ambesh et al. reported a significant decrease in the incidence and severity of FIC in patients who perform a Huffing maneuver just before intravenous fentanyl injection [11].

Various interventions have been performed to reduce the incidence of FIC, however none of which alone have demonstrated satisfactory reducing effect. In this study, the reducing effect of FIC was investigated in an integrated protocol with the simultaneous use of lidocaine injection along with the Huffing maneuvers before induction of anesthesia. We aimed to evaluate the incidence of FIC, along with its severity after lidocaine injection, Huffing maneuver and a combination of both in order to provide guidelines for anesthesiologists worldwide.

\section{Material and method}

This study, which is a prospective randomized controlled trial, was performed on 400 patients who underwent fentanyl injection in hospitals affiliated to Shiraz University of Medical Sciences in 2018. Patients with nonemergency surgery aged 14 to 69 years were included in the study, while patients with a history of asthma, chronic obstructive pulmonary disease, chronic cough, upper respiratory tract infection in the 2 weeks before surgery, a history of smoking, steroid or bronchodilator treatment, or people taking ACE inhibitors were excluded.

The study was approved by the ethics committee of Shiraz University of Medical Sciences (IR.SUMS.MED.REC.1394.61), the institutional review board, and Iranian Registry of Clinical Trials (IRCT.ir; date: 09/03/2018No. IRCT20141009019470N74) and conducted in compliance with local regulatory requirements, Good Clinical Practice (GCP), and the Declaration of Helsinki [12]. All stages of the research and the goals were explained by the researcher to all the patients and written informed consent was obtained from all patients or their legally authorized representatives. Also, it is ensured that the reluctance to participate in the study has no effect on their treatment process and they can leave our study whenever they wish.

Regarding sample size estimation, assuming 95\% confidence level (first type alpha error 5\%) and $80 \%$ power and considering the observation of at least 0.30 and expecting differences in treatment results between the intervention (0.25) and control (0.55) groups, we calculated that a total of 164 patients (i.e. 41 cases in the intervention group and 41 in the control group) would be required for the analysis (Fleiss with $\mathrm{CC}$ ). By applying a design effect of 2 based on our inclusion and exclusion criteria and multicentral study, reaching a total estimation of 328 patients.

The Patients were then divided into four groups of 100 which were equivalent in sex and age, based on block randomization.

Group 1 (Integrated Protocol Group): In this group, 1 min before fentanyl injection, $2 \mathrm{mg} / \mathrm{kg}$ lidocaine was rapidly (during $10 \mathrm{~s}$ ) administered through the peripheral iv line for the patient and after $55 \mathrm{~s}$, Huffing maneuver was performed after a deep inspiration for less than $5 \mathrm{~s}$, and subsequently the patient was administered $2.5 \mu \mathrm{g} / \mathrm{kg}$ fentanyl. Huffing maneuver was performed in accordance with standard procedures [13], in which patients were advised to start with diaphragmatic breathing in every postural drainage position. This was followed by thoracic expansion exercises and diaphragmatic breathing again after the patient had relaxed sufficiently. Then two huffs followed, with chest compression alternating with relaxed diaphragmatic breathing (maximum forced expiration from mid-lung volume). The patients coughed when required. This procedure was carried out without any assistance. The act of huffing lasted $<5 \mathrm{~s}$ 
and was standardized to all patients. Regarding bolus injection of lidocaine, since slow injection of fentanyl above $30 \mathrm{~s}$ seems to be effective in preventing FIC, [7] bolus injection was performed during $10 \mathrm{~s}$ in all lidocaine groups.

Group 2 (lidocaine group): In this group, 1 min before fentanyl injection, $2 \mathrm{mg} / \mathrm{kg}$ lidocaine was rapidly (during $10 \mathrm{~s}$ ) administered through the peripheral iv line for the patient and then fentanyl was was rapidly administered through the peripheral iv line for the patient at $2.5 \mu \mathrm{g} /$ $\mathrm{kg}$.

Group 3 (Huffing group): In this group, 1 min before fentanyl injection, the Huffing maneuver was performed after a deep inspiration for less than $5 \mathrm{~s}$ and then fentanyl was rapidly administered through the peripheral iv line for a rate of $2.5 \mu \mathrm{g} / \mathrm{kg}$.

Group 4 (control group): In this group, 1 min before the administration of fentanyl, an equal volume of normal saline with the lidocaine group was rapidly administered through the peripheral iv line for the patient and then fentanyl was rapidly administered through the peripheral iv line at the rate of $2.5 \mu \mathrm{g} / \mathrm{kg}$.

Then the patients were monitored by a blinded research assistant for $2 \mathrm{~min}$, which was blinded from the patients grouping, and the presence or absence of reflex cough as well as the severity of cough (as 1-2 coughs assigned as first-degree cough, $3-4$ as grade 2 , while 5 coughs and more than 5 grade 3) was reported in each patient.

During these $2 \mathrm{~min}$, all secondary changes related to fentanyl such as changes in heart rate or changes in blood pressure that required intervention were recorded. For the induction of anesthesia, propofol was administered for all patients if no coughs were recorded during the initial 2 min after fentanyl injection, while in cases where coughs persisted, propofol injection was pushed forward and induction was performed. All data were collected and entered into SPSS statistical software for statistical analysis and analyzed using the chi-square test for qualitative variables and student test for quantitative variables. $P$-value $<0.05$ was also considered significant.

\section{Results}

A total of 400 patients in four groups were included in the study during 2018. Patients were matched in terms of age and sex in groups $(P>0.05)$. The baseline demographic data of the patients is demonstrated in Table 1.

As demonstrated in Table 1, the frequency of FIC in intervention groups was significantly lower than the control group $(P$ value $<0.001)$, also this symptom was significantly lower in the first group (integrated protocol) compared to the second groups (lidocaine injection alone; $P<0.001$ ) And the third (Huffing maneuver alone; $P=0.009)$. Furthermore, comparing the second and third group (lidocaine injection alone vs. Huffing maneuver alone), the rates were significantly lower in the Huffing maneuver group $(P$ value $<0.001)$.

In the control group, 13 cases $(13 \%)$ had moderate coughs and 4 cases (4\%) had severe coughs, while in the intervention groups, moderate and severe cough was not observed, while this difference between the control and intervention groups was also statistically significant $(P$ value $<0.001)$.

\section{Discussion}

During a cough, the pressure inside the chest reaches $300 \mathrm{mmHg}$ and the expiratory air velocity reaches 500 miles per hour [14]. This pressure and speed caused by coughing can cause adverse effects such as headache, dizziness, myalgia, hoarseness, urinary incontinence, and even rib fractures, especially in patients with low bone density $[15,16]$. Fentanyl is widely used in the operating room to anesthetize patients, but a typical complication

Table 1 Demographic and Fentanyl-induced cough frequency and severity based on the administration of Lidocaine, Huffing Maneuver, or combined therapy

\begin{tabular}{|c|c|c|c|c|c|}
\hline \multirow[t]{2}{*}{ Variables } & \multicolumn{4}{|l|}{ Groups $n=400$} & \multirow{2}{*}{$\begin{array}{l}P \text { - } \\
\text { value* }\end{array}$} \\
\hline & $\begin{array}{l}\text { Integrated Protocol Group } n= \\
100\end{array}$ & $\begin{array}{l}\text { Lidocaine group } n= \\
100\end{array}$ & $\begin{array}{l}\text { Huffing group } n= \\
100\end{array}$ & $\begin{array}{l}\text { Control group } n= \\
100\end{array}$ & \\
\hline Age & $42.67 \pm 12.73$ & $40.99 \pm 10.75$ & $44.05 \pm 14.84$ & $41.24 \pm 15.03$ & 0.345 \\
\hline \multicolumn{6}{|l|}{ Sex } \\
\hline Male & $45(45 \%)$ & $50(50 \%)$ & 47 (47\%) & 47 (47\%) & \multirow[t]{2}{*}{0.916} \\
\hline Female & $55(55 \%)$ & $50(50 \%)$ & $53(53 \%)$ & 53 (53\%) & \\
\hline $\begin{array}{l}\text { Fentanyl-induced cough } \\
\text { frequency }\end{array}$ & $9(9 \%)$ & $45(45 \%)$ & $22(22 \%)$ & $75(75 \%)$ & $<0.001$ \\
\hline \multicolumn{6}{|l|}{ Severity } \\
\hline Moderate & $0(0 \%)$ & $0(0 \%)$ & $0(0 \%)$ & $13(13 \%)$ & \multirow[t]{2}{*}{$<0.001$} \\
\hline Severe & $0(0 \%)$ & $0(0 \%)$ & $0(0 \%)$ & $4(4 \%)$ & \\
\hline
\end{tabular}

* ANOVA test for age; Chi-square test for sex, and cough evaluation 
of this valuable drug in patients in anesthesia induction is cough $[17,18]$.

In the present study, which aimed to combine the effects of Huffing maneuver and lidocaine injection before fentanyl administration to reduce the complication of FIC, it was found that FIC is prevalent after fentanyl injection in patients who no interventions in this regard was applied, which accounted for $75 \%$ of the patients in the control group. Our higher rates compared to most studies in this field, such as the study of Lin et al. [2], which reported a prevalence of $65 \%$, and the study of Chandra et al., [19] which reported a prevalence of $34 \%$, may have been due to the wider age range and the larger number of samples in this study.

Based on our data, the prevalence of cough was $45 \%$ in patients who received $2 \mu \mathrm{g} / \mathrm{kg}$ lidocaine before fentanyl injection, which was much higher compared to other studies such as Gecaj-Gashi et al. [20] who reported a prevalence of $16 \%$ with $1 \mu \mathrm{g} / \mathrm{kg}$ lidocaine injection and $22 \%$ with $0.5 \mu \mathrm{g} / \mathrm{kg}$ injection and Chandra et al. who reported a prevalence of $13 \%$ [21]. This could indicate that increasing the dose of lidocaine, as shown in another study by Chandra et al. [22], increased the prevalence of this complication. However, further studies in this regard are justified.

In our study, the incidence of cough was reported to be $22 \%$ in patients who underwent Huffing maneuvers before fentanyl injection. By applying a combination therapy, this rate was only observed in $9 \%$ of the patients, which was significantly lower compared to the control group. In this regard, a study by Ambesh et al. [11] showed that patients who underwent Huffing maneuvers before fentanyl injection had significantly lower incidences of drug-induced cough in the control group, however a study on the effect of the combination of Huffing maneuver along with lidocaine injection has not been previously reported till date. Also in the present study, similar to the study by Ambesh et al. [11], the severity of drug-induced cough in the intervention groups was significantly lower than the control group, however, in other studies, no significant relationship was observed between the groups [2,21].

Another point of view which should be assessed is that the time of this report was during the ongoing coronavirus disease (COVID-19) pandemic, in which many countries have been affected by the disease and cough being the main transmission route of the virus [23-26]. However, the diagnosis and treatment of these patients are still not completely sufficient [27-30]. Furthermore, many patients are asymptomatic and undiagnosed and undergo various surgical procedures [30]. Aminnejad et al. [31] pointed out the value of preventing FIC to reduce the virus transmission and possible infection of healthcare workers, which is among the most damaging consequences of this pandemic among other aspects [32, 33]. As our data demonstrated, the Huffing maneuver was more effective in reducing the frequency of FIC compared to lidocaine injection. However, both techniques had significant reduction in FIC frequency compared to the control group. Therefore, by utilizing a combination approach in patients during anesthesia, remarkable reductions in FIC frequency can be obtained, as also has been demonstrated in our results.

Among the limitations and aspects that should be considered in our study is that factors such as increasing age, cigarette smoking, prior epidural injection of lidocaine or a priming dose of vecuronium have been reported to be associated with FIC, which were all excluded and matched among our groups. Therefore, evaluation of such features was not possible in our study [34-36].

\section{Conclusion}

By using a combination of lidocaine injection along and Huffing maneuver, better results can be obtained in reducing the frequency, and also the severity of cough followed by fentanyl injection. These results can be beneficial for anesthesiologists worldwide to avoid undesirable complications of FIC.

\section{Acknowledgments \\ The authors would like to thank Reza Shahriarirad for assisting in the manuscript preparation.}

\section{Authors' contributions}

L.D. and P.V. contributed to the conception or design of the work. M.E. contributed to the acquisition and analysis of the data. F.B. contributed to the interpretation of the data for the work. P.V. drafted the work. L.D. revised it critically for important intellectual content. All authors approved the final version to be published.

\section{Funding}

No specific funding was obtained for this study.

Availability of data and materials

The dataset supporting the conclusions of this article is included within the article. Please contact the corresponding author in case of requiring any further information.

\section{Declarations}

Ethics approval and consent to participate

This study obtained ethics approval from the Institutional Review Board of Shiraz University of Medical Sciences (IR.SUMS.MED.REC.1394.61). The study was registered on IRCT.IR with the following identifier: IRCT.ir; date: 09/03/ 2018-No. IRCT20141009019470N74. All participants were provided with written consent and were guaranteed that their information would be safeguarded by the researcher.

Consent for publication

Not applicable.

Competing interests

All authors declare that they have no competing interests. 
Received: 28 January 2021 Accepted: 22 March 2021

Published online: 27 March 2021

\section{References}

1. Lin J-A, Yeh C-C, Lee M-S, Wu C-T, Lin S-L, Wong C-S. Prolonged injection time and light smoking decrease the incidence of fentanyl-induced cough. Anesth Analg. 2005:101(3):670-4.

2. Lin C-S, Sun W-Z, Chan W-H, Lin C-J, Yeh H-M, Mok MS. Intravenous lidocaine and ephedrine, but not propofol, suppress fentanyl-induced cough. Can J Anesth. 2004;51(7):654-9.

3. Tweed WA, Dakin D. Explosive coughing after bolus fentanyl injection. Anesth Analg. 2001;92(6):1442-3.

4. Ambesh S, Singh N, Srivastava K. Fentanyl induced coughing caused lifethreatening airway obstruction in a patient with arteriovenous malformation of tongue and hypopharynx. Int J Anesthesiol. 2009;20(20):7.

5. Ping-Wing L, Chung-Hsi H, Ya-Churn C. Terbutaline inhalation suppresses fentanyl-induced coughing. Can J Anaesth. 1996;43(12):1216.

6. Agarwal A, Azim A, Ambesh S, Bose N, Dhiraj S, Sahu D, et al. Salbutamol, beclomethasone or sodium chromoglycate suppress coughing induced byiv fentanyl. Can J Anaesth. 2003;50(3):297.

7. Kim JE, Min SK, Chae YJ, Lee YJ, Moon BK, Kim JY. Pharmacological and nonpharmacological prevention of fentanyl-induced cough: a meta-analysis. J Anesth. 2014;28(2):257-66.

8. Poulton TJ, JAMES FM. Cough suppression by lidocaine. Anesthesiology. 1979;50(5):470-2.

9. Brauer S. Nonpharmacologic airway clearance therapies. Aust J Physiother. 2007;53(1):67.

10. Deck D, Winston L, Katzung B, Masters S, Trevor A. Basic Clin Pharmacol; 2012.

11. Ambesh S, Singh N, Gupta D, Singh P, Singh U. A huffing manoeuvre, immediately before induction of anaesthesia, prevents fentanyl-induced coughing: a prospective, randomized, and controlled study. Br J Anaesth. 2010;104(1):40-3.

12. Association WM. World medical association declaration of Helsinki: ethical principles for medical research involving human subjects. JAMA. 2013; 310(20):2191-4.

13. Gaskell DV. The Brompton hospital guide to chest physiotherapy: WileyBlackwell; 1977.

14. Comroe J. Special acts involving breathing. Physiology of respiration: an introductory text. Chicago: Yearbook Medical Publishers; 1974.

15. Hanak V, Hartman TE, Ryu JH. Cough-induced rib fractures. In: Mayo Clinic Proceedings: Elsevier; 2005. p. 879-82.

16. Irwin RS, Baumann MH, Bolser DC, Boulet L-P, Braman SS, Brightling CE, et al. Diagnosis and management of cough executive summary: ACCP evidence-based clinical practice guidelines. Chest J. 2006;129(1_suppl):1S$23 S$.

17. Kato R, Ross S, Foex P. Fentanyl protects the heart against ischaemic injury via opioid receptors, adenosine A1 receptors and KATP channel linked mechanisms in rats. Br J Anaesth. 2000;84(2):204-14.

18. Weiskopf RB, Eger El II, Noorani TM, Daniel M. Fentanyl, esmolol, and clonidine blunt the transient cardiovascular stimulation induced by desflurane in humans. Anesthesiology. 1994;8:15S0-55.

19. Pandey CK, Raza M, Ranjan R, Singhal V, Kumar M, Lakra A, et al. Intravenous lidocaine $0.5 \mathrm{mg} \cdot \mathrm{kg}-1$ effectively suppresses fentanyl-induced cough. Can J Anesth. 2005:52(2):172-5.

20. Gecaj-Gashi A, Nikolova-Todorova Z, Ismaili-Jaha V, Gashi M. Intravenous lidocaine suppresses fentanyl-induced cough in children. Cough. 2013;15(1): 20.

21. Pandey CK, Raza M, Ranjan R, Lakra A, Agarwal A, Singh U, et al. Intravenous lidocaine suppresses fentanyl-induced coughing: a double-blind, prospective, randomized placebo-controlled study. Anesth Analg. 2004;99(6): 1696-8

22. Schlimp CJ, Wiedermann FJ. Does fentanyl-induced cough justify pretreatment with IV lidocaine 2 mg/kg-1. Can J Anaesth. 2005;52(2):207.

23. Shahriarirad R, Khodamoradi Z, Erfani A, Hosseinpour H, Ranjbar K, Emami Y, et al. Epidemiological and clinical features of 2019 novel coronavirus diseases (COVID-19) in the south of Iran. BMC Infect Dis. 2020;20(1):1-12.

24. Erfani A, Shahriarirad R, Ranjbar K, Mirahmadizadeh A, Moghadami M. Knowledge, attitude and practice toward the novel coronavirus (COVID-19) outbreak: a population-based survey in Iran. Bull World Health Organ. 2020; $30(10.2471)$
25. Mirahmadizadeh A, Ranjbar K, Shahriarirad R, Erfani A, Ghaem H, Jafari K, et al. Evaluation of students' attitude and emotions towards the sudden closure of schools during the COVID-19 pandemic: a cross-sectional study. BMC Psychol. 2020;8(1):1-7.

26. Ranjbar K, Hosseinpour H, Shahriarirad R, Ghaem H, Jafari K, Rahimi T, et al. Students' attitude and sleep pattern during school closure following COVID19 pandemic quarantine: a web-based survey in south of Iran. Environ Health Prev Med. 2021;26(1):33.

27. Dashti AS, Ebrahimi K, Shahriarirad R, Ghotbabadi SH, Aminnia S. COVID-19 pandemic in the disguise of multi system inflammatory syndrome in children: a case series; 2021.

28. Ranjbar K, Shahriarirad R, Erfani A, Khodamoradi Z, Saadi MHG, Mirahmadizadeh A, et al. Methylprednisolone or dexamethasone, which one is the superior corticosteroid in the treatment of hospitalized COVID-19 patients: a triple-blinded randomized controlled trial; 2021.

29. Shahriarirad R, Fallahi M. TB and the COVID-19 pandemic: brothers in arms against lung health. Int J Tuberc Lung Dis. 2020;24(10):1126-7.

30. Shahriarirad R, Sarkari B. COVID-19: clinical or laboratory diagnosis? A matter of debate. Trop Dr. 2020;51(1):131-2. https://doi.org/10.1177/004947552094 5446.

31. Aminnejad R, Salimi A, Saeidi M. Lidocaine during intubation and extubation in patients with coronavirus disease (COVID-19). Can J Anaesth. 2020;67(6):759. https://doi.org/10.1007/s12630-020-01627-2. Epub 2020 Mar 16.

32. Sabetian G, Moghadami M, Haghighi LHF, Fallahi MJ, Shahriarirad R, Asmarian N, et al. COVID-19 infection among healthcare workers: a crosssectional study in Southwest Iran; 2020.

33. Shahriarirad R, Erfani A, Ranjbar K, Bazrafshan A, Mirahmadizadeh A. The mental health impact of COVID-19 outbreak: a Nationwide Survey in Iran. Int J Ment Health Syst. 2021;15(1):19. https://doi.org/10.1186/s13033-02100445-3.

34. Yeh CC, Wu CT, Huh BK, Lee MS, Lin SL. M JS, Wong CS: premedication with intravenous low-dose ketamine suppresses fentanyl-induced cough. J Clin Anesth. 2007:19(1):53-6.

35. Tang Q, Qian Y, Zhang Q, Yang J, Wang Z. Effects of different priming doses of propofol on fentanyl-induced cough during anesthesia induction: a preliminary randomized controlled study. Ups J Med Sci. 2010;115(2):121-4.

36. Oshima T, Kasuya Y, Okumura Y, Murakami T, Dohi S. Identification of independent risk factors for fentanyl-induced cough. Can J Anaesth. 2006; 53(8):753-8.

\section{Publisher's Note}

Springer Nature remains neutral with regard to jurisdictional claims in published maps and institutional affiliations.

Ready to submit your research? Choose BMC and benefit from:

- fast, convenient online submission

- thorough peer review by experienced researchers in your field

- rapid publication on acceptance

- support for research data, including large and complex data types

- gold Open Access which fosters wider collaboration and increased citations

- maximum visibility for your research: over $100 \mathrm{M}$ website views per year

At $\mathrm{BMC}$, research is always in progress.

Learn more biomedcentral.com/submissions 